\title{
Identification of Ixodes ricinus blood meals using an automated protocol with high resolution melting analysis (HRMA) reveals the importance of domestic dogs as larval tick hosts in Italian alpine forests
}

\author{
Margherita Collini ${ }^{1} 2^{*}$, Francesca Albonico ${ }^{1,2}$, Roberto Rosà ${ }^{1}$, Valentina Tagliapietra ${ }^{1}$, Daniele Arnoldi ${ }^{1}$,
} Lorenza Conterno ${ }^{3}$, Chiara Rossi ${ }^{1}$, Michele Mortarino ${ }^{2}$, Annapaola Rizzoli ${ }^{1}$ and Heidi Christine Hauffe

\begin{abstract}
Background: In Europe, Ixodes ricinus L. is the main vector of a variety of zoonotic pathogens, acquired through blood meals taken once per stage from a vertebrate host. Defining the main tick hosts in a given area is important for planning public health interventions; however, until recently, no robust molecular methods existed for blood meal identification from questing ticks. Here we improved the time- and cost-effectiveness of an HRMA protocol for blood meal analysis and used it to identify blood meal sources of sheep tick larvae from Italian alpine forests.

Methods: Nine hundred questing nymphs were collected using blanket-dragging in 18 extensive forests and 12 forest patches close to rural villages in the Province of Trento. Total DNA was either extracted manually, with the QIAamp DNA Investigator kit, or automatically using the KingFisher ${ }^{\text {TM }}$ Flex Magnetic Particle Processors (KingFisher Cell and Tissue DNA Kit). Host DNA was amplified with six independent host group real-time PCR reactions and identified by means of HRMA. Statistical analyses were performed in R to assess the variables important for achieving successful identification and to compare host use in the two types of forest.

Results: Automating DNA extraction improved time- and cost-effectiveness of the HRMA protocol, but identification success fell to 22.4\% (KingFisher ${ }^{\text {TM) }}$ ) from 55.1\% (QIAamp), with larval hosts identified in 215 of 848 questing nymphs; 23 mixed blood meals were noted. However, the list of hosts targeted by our primer sets was extended, improving the potential of the method. Host identification to species or genus level was possible for 137 and 102 blood meals, respectively. The most common hosts were Rodentia (28.9\%) and, unexpectedly, Carnivora (28.4\%), with domestic dogs accounting for $21.3 \%$ of all larval blood meals. Overall, Cetartiodactyla species fed $17.2 \%$ of larvae. Passeriformes (14.6\%) fed a significantly higher proportion of larvae in forest patches (22.3\%) than in extensive forest (9.6\%), while Soricomorpha (10.9\%) were more important hosts in extensive forest (15.2\%) than in forest patches (4.3\%).

(Continued on next page)
\end{abstract}

\footnotetext{
*Correspondence: collini.margherita@gmail.com

'Department of Biodiversity and Molecular Ecology, Research and Innovation

Centre, Fondazione Edmund Mach, San Michele all'Adige, Trento, Italy

${ }^{2}$ Department of Veterinary Medicine, Università degli Studi di Milano, Milan,

Italy

Full list of author information is available at the end of the article
} 
(Continued from previous page)

Conclusions: The HRMA protocol for blood meal analysis is a valuable tool in the study of feeding ecology of sheep ticks, especially with the cost- and time- reductions introduced here. To our knowledge, we show for the first time that domestic dogs are important larval hosts in the Alps, which may have possible implications for tick-borne disease cycles in urbanized areas.

Keywords: Ixodes ricinus, Feeding ecology, Nymphs, Tick-borne disease, Blood meal analysis, Vertebrate hosts, Canis lupus familiaris

\section{Background}

The sheep tick Ixodes ricinus L. is the main European vector of a variety of pathogens of medical and veterinary importance [1-3]. This parasite takes blood meals on many wild and domestic vertebrate species (as well as humans), which may simply feed the tick (incompetent or maintenance hosts) or feed the tick and transmit the etiological agents of disease to the vector (competent hosts [4]). Thus, the epidemiology of tick-borne diseases (TBDs) depends on host, vector and pathogen dynamics, as well as on the complex network of interactions between them. Understanding tick feeding ecology in relation to the composition of vertebrate host communities is critical to predicting disease risk for public health and improving disease control strategies [5-8].

A blood meal is essential for the sheep tick to moult from one stage to the next, from larva to nymph to adult. Following the blood meal, the larvae and nymphs drop off the host and hide in the leaf litter for several months up to more than a year (depending on climatic conditions), before moulting to the next stage and waiting on the vegetation for the next host, which they detect using specialized sensors on their forelegs ('questing'). Therefore, until recently, estimating host exploitation required capturing live hosts and counting feeding ticks, which is labour intensive and may be biased $[9,10]$.

Although molecular methods have been used successfully to identify host DNA in blood meals of several arthropod vectors, their application to questing ticks is more challenging since the blood meals will have been digested (and therefore degraded) for a year or more $[6,7,11]$. In fact, genetic blood meal identification for questing ticks with available methods was not considered sufficiently robust for application in field studies, and questions had been raised concerning their susceptibility to contamination $[12,13]$. Recently, some of us developed an HRMA protocol to allow the identification of 21 of the most important vertebrate alpine hosts from field-collected questing sheep tick nymphs [11]. In this previous paper, we limited the sample size to the number of ticks necessary to provide proof of principle of the method. In the present study, we improved the timeand cost-effectiveness of this method with several modifications, and applied this new protocol to a large number of $I$. ricinus nymphs in order to evaluate tick host use in forest environments in the northeastern Italian Alps.

\section{Methods \\ Tick sampling}

From April to June 2012 and 2013, samples of 30 questing nymphs each were collected using standard blanketdragging [14] from 30 deciduous and/or coniferous forest sites throughout the Province of Trento (Fig. 1; Table 1). Since forest extent has a significant effect on vertebrate community composition, the selected sites consisted of 18 extensive forests (EXTF) and 12 forest patches near human settlements (PATF). Humans typically visit extensive forest (EXTF) for work-related activities (e.g. rangers, lumberjacks, farmers, hunters) and forest patches (PATF) closer to villages for leisure activities (dog walking, hiking, fishing, mushrooming). Each tick was removed individually from the blanket using sterile forceps, placed in a sterile $2 \mathrm{ml}$ microcentrifuge tube, transported live to the Fondazione E. Mach laboratories and frozen at $-80{ }^{\circ} \mathrm{C}$ until DNA extraction.

\section{DNA extraction and larval blood meal source identification by real-time HRMA}

Each tick was confirmed morphologically as I. ricinus using a dissecting microscope at $50 \times$ magnification following Cringoli et al. [15] then washed twice in DNA-free distilled water to eliminate surface contaminants. For 99 nymphs (including 52 used in [11]), DNA was extracted manually using the QiaAmp DNA Investigator Kit (Purification of total DNA from nail clipping and hair Protocol; Qiagen, Valencia, CA, USA) following Collini et al. [11]. For the remaining 749 nymphs, blood meal identification also followed Collini et al. [11] except that total DNA extraction was performed automatically using the KingFisher $^{\mathrm{max}}$ Flex Magnetic Particle Processors with the KingFisher Cell and Tissue DNA Kit (Thermo Fisher Scientific, Vantaa, Finland), in an attempt to improve speed and efficiency. Sample lysis was performed under a biological laminar flow hood (UV-sterilized) as follows: a single nymph was placed in a sterile $2 \mathrm{ml}$ microcentrifuge tube containing $180 \mu \mathrm{l}$ ATL buffer (Qiagen, Valencia, CA, USA), $30 \mu \mathrm{l}$ DTT $1 \mathrm{M}$ (Sigma-Aldrich, Saint Louis, USA) 


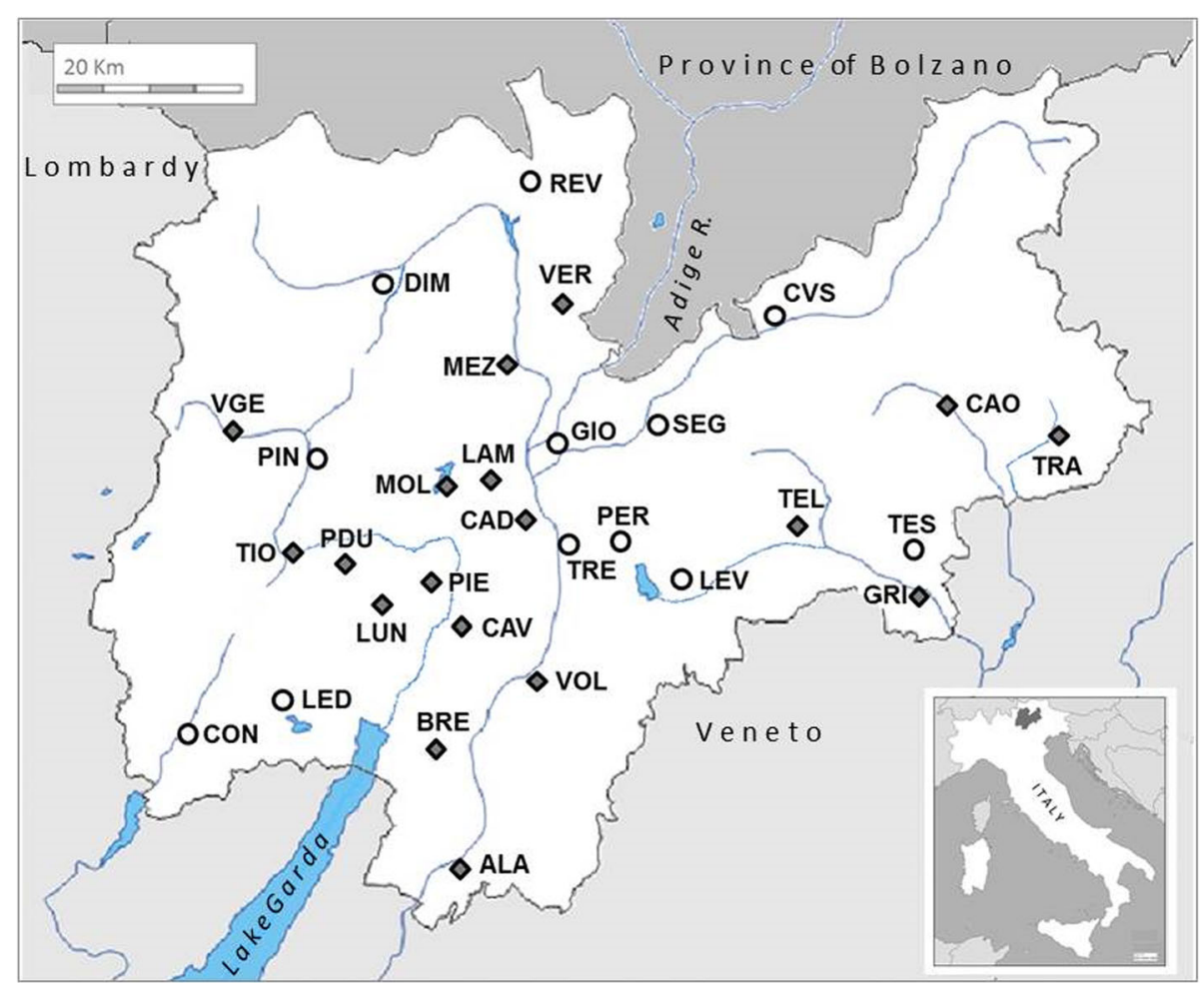

Fig. 1 Location of sampling sites in the Province of Trento, northeastern Italy. Sampling site abbreviations are listed with the nearest locality to sampling site in Table 1. Open circles indicate sampling sites in forest patches (PATF) and grey diamonds indicate sites in or at the edge of extensive forests (EXTF)

and $20 \mu$ Proteinase K (KingFisher ${ }^{\mathrm{m}}$ Cell and Tissue DNA Kit; Thermo Fisher Scientific, Vantaa, Finland), and cut into small pieces with a sterile scalpel. Samples were digested overnight by incubating at $56{ }^{\circ} \mathrm{C}$. Purification followed the manufacturer's protocol, except that total DNA was eluted in $80 \mu \mathrm{l}$ of elution buffer (Thermo Fisher Scientific) instead than $150 \mu \mathrm{l}$. DNA was stored at $-20{ }^{\circ} \mathrm{C}$ until use. To check for cross-contamination, three negative controls were included in each 96-well extraction plate. DNA of target host species (positive controls for real-time HRMA) was extracted from host tissues and/or from engorged ticks collected from the host while feeding using the methods above (these samples were available from previous or ongoing projects at the Fondazione Edmund Mach, Italy, and stored in 70\% ethanol solution at $\left.-80{ }^{\circ} \mathrm{C}\right)$. No tissues or engorged ticks were available for Sorex araneus or Crocidura russula.

Host DNA from the larval blood meal remnant in questing nymphs was amplified using group-specific primers and reaction mix conditions as already described [11]. In each real-time HRMA reaction, a positive control sample for each target species and a negative control (DNA-free water) were included. A QIAgility robotic workstation (Qiagen, Valencia, CA, USA) was used for automated high precision reaction setup. Real-time HRMA was performed in a Rotor-Gene ${ }^{\mathrm{TM}} 6000$ real-time cycler (Corbett Life
Science) with a 72-well rotor, according to Collini et al. [11] with the following modifications: initiation step $95{ }^{\circ} \mathrm{C}$ for $5 \mathrm{~min}, 55$ annealing and elongation cycles at $95^{\circ} \mathrm{C}$ for $15 \mathrm{~s}$ and $\mathrm{T}_{a}\left({ }^{\circ} \mathrm{C}\right)$ of the group-specific primer set for $15 \mathrm{~s}$, directly followed by HRM with a pre-melt conditioning step of $70{ }^{\circ} \mathrm{C}$ for $90 \mathrm{~s}$, then increasing the temperature from $70{ }^{\circ} \mathrm{C}$ to $95{ }^{\circ} \mathrm{C}$, by $0.2{ }^{\circ} \mathrm{C}$ steps for $2 \mathrm{~s}$ each. The Rotor-Gene 6000 Series Software v. 1.7 was used to control amplifications and to perform HRMA to identify the blood meal source by means of both normalized and derivative melting profile shapes and melting temperatures $\left(T_{m}{ }^{\circ} \mathrm{C}\right)$, as described in Collini et al. [11]. To check that the DNA extraction protocol modifications and change of real-time HRM instrument did not introduce errors in blood meal identification, the first few amplified fragments from questing nymphs were sequenced; subsequently, since there were no errors in blood meal identification, only amplicons with non-specific melting properties were investigated via capillary electrophoresis and/or sequence analysis. Capillary electrophoresis was carried out using the QIAxcel system (Qiagen, Valencia, CA, USA) with a DNA High Resolution Cartridge and the QX 15 bp-3 Kb size marker, using the OM500 method; results were analysed with QIAxcel ScreenGel 1.0.2.0. For sequencing, real-time PCR products were purified with Exo-SAP-IT ${ }^{\mathrm{max}}$ (GE Healthcare, Little Chalfont, England); both forward and 
Table 1 Sampling sites, collection data and HRMA blood meal analysis results according to DNA extraction method

\begin{tabular}{|c|c|c|c|c|c|c|}
\hline DNA extraction method & $\begin{array}{l}\text { Sampling } \\
\text { site }^{\mathrm{a}}\end{array}$ & $\begin{array}{l}\text { Nearest locality to } \\
\text { sampling site }\end{array}$ & $\begin{array}{l}\text { Sampling } \\
\text { time }\end{array}$ & $\begin{array}{l}\% \\
\text { identification } \\
\text { success }^{\mathrm{b}}\end{array}$ & $\begin{array}{l}\text { No. of } \\
\text { mixed blood } \\
\text { meals }\end{array}$ & $\begin{array}{l}\text { Mean identification } \\
\text { success (\%) }\end{array}$ \\
\hline \multirow{7}{*}{$\begin{array}{l}\text { QiaAMP® DNA } \\
\text { Investigator }\end{array}$} & $\mathrm{BRE}^{\mathrm{C}}$ & Brentonico & May 2012 & $46.7(7 / 15)$ & 1 & \multirow[t]{7}{*}{55.1} \\
\hline & $C A D^{c}$ & Cadine & May 2012 & $35.7(5 / 14)$ & 0 & \\
\hline & CON & Condino & April 2012 & $69.2(9 / 13)$ & 4 & \\
\hline & $\mathrm{GlO}^{c}$ & Giovo & April 2013 & $43.8(7 / 16)$ & 1 & \\
\hline & $\mathrm{GRI}^{\mathrm{b}}$ & Grigno Valsugana & April 2013 & $31.3(5 / 16)$ & 0 & \\
\hline & PIE & Pietramurata & May 2012 & $92.3(12 / 13)$ & 2 & \\
\hline & TRA & Transacqua & June 2012 & $66.7(8 / 12)$ & 2 & \\
\hline \multirow{27}{*}{$\begin{array}{l}\text { ThermoScientific } \\
\text { KingFisher }^{T M}\end{array}$} & ALA & Ala & May 2012 & $33.3(10 / 30)$ & 2 & \multirow[t]{27}{*}{22.4} \\
\hline & $\mathrm{BRE}^{\mathrm{C}}$ & Brentonico & May 2012 & $29.4(5 / 17)$ & 0 & \\
\hline & CAO & Caoria & April 2013 & $30.0(9 / 30)$ & 2 & \\
\hline & $C A D^{c}$ & Cadine & May 2012 & $25.0(2 / 8)$ & 0 & \\
\hline & CAV & Cavedine & April 2013 & $20.0(6 / 30)$ & 0 & \\
\hline & CVS & Cavalese & May 2012 & $21.7(5 / 23)$ & 0 & \\
\hline & DIM & Dimaro & May 2013 & $33.3(10 / 30)$ & 2 & \\
\hline & $\mathrm{GIO}^{c}$ & Giovo & April 2013 & $31.3(5 / 16)$ & 0 & \\
\hline & $\mathrm{GRI}^{\mathrm{c}}$ & Grigno Valsugana & April 2013 & $43.8(7 / 16)$ & 0 & \\
\hline & LAM & Laghi di Lamar & May 2012 & $9.7(3 / 31)$ & 0 & \\
\hline & LED & Ledro & May 2012 & $20.0(6 / 30)$ & 0 & \\
\hline & LEV & Levico & April 2012 & $26.7(8 / 30)$ & 0 & \\
\hline & LUN & Lundo & May 2012 & $6.7(2 / 30)$ & 0 & \\
\hline & MEZ & Mezzocorona & June 2012 & $16.7(5 / 30)$ & 2 & \\
\hline & $\mathrm{MOL}$ & Molveno & May 2012 & $3.3(1 / 30)$ & 0 & \\
\hline & PDU & Passo del Durone & June 2012 & $32.4(11 / 34)$ & 0 & \\
\hline & PER & Pergine & April 2012 & $20.0(6 / 30)$ & 1 & \\
\hline & PIN & Pinzolo & May 2012 & $20.0(6 / 30)$ & 0 & \\
\hline & REV & Revò & May 2012 & $13.3(4 / 30)$ & 0 & \\
\hline & SEG & Segonzano & May 2012 & $23.3(7 / 30)$ & 1 & \\
\hline & TEL & Telve & June 2012 & $13.3(4 / 30)$ & 1 & \\
\hline & TES & Tesino & June 2012 & $20.0(6 / 30)$ & 0 & \\
\hline & $\mathrm{TIO}$ & Tione di Trento & May 2012 & $10.0(3 / 30)$ & 0 & \\
\hline & TRE & Trento & May 2013 & $17.6(6 / 34)$ & 0 & \\
\hline & VER & Vervò & May 2012 & $20.0(6 / 30)$ & 0 & \\
\hline & VGE & Val Genova & May 2013 & $13.3(4 / 30)$ & 0 & \\
\hline & VOL & Volano & May 2012 & $50.0(15 / 30)$ & 2 & \\
\hline
\end{tabular}

${ }^{a}$ Abbreviations as in Fig. 1

${ }^{b}$ Number of nymphs with identified blood meal/number of nymphs analysed (as shown in parentheses)

'Site with samples extracted with either QiaAMP ${ }^{\circledR}$ DNA Investigator or ThermoScientific KingFisher ${ }^{\mathrm{TM}}$ methods

reverse strands were sequenced on an $\mathrm{ABI} 3130 \mathrm{XL}$ using Big Dye Terminator v3.1 (Applied Biosystems, Foster City, CA, USA). Raw sequences were checked and a consensus sequence created using the software Sequencher v. 5.1; a BLASTn search (http://blast.ncbi.nlm.nih.gov/Blast.cgi) was carried out to verify amplicon identity.

\section{Statistical analysis}

A Multiple Linear Regression Model was used to assess variation in the proportion of ticks with an identified blood meal (identification success) in relation to the following explanatory variables: DNA extraction method, sampling year, sampling month and habitat type. Tick hosts were 
grouped according to taxonomic order (Rodentia, Soricomorpha, Passeriformes, Carnivora, Cetartiodactyla) and a chi-square test was used to compare the proportion of identified blood meals in the different host groups between EXTF and PATF sites. Statistical analyses were performed using R software [16].

\section{Results}

Out of the 900 sheep tick nymphs collected from 30 sites in Province of Trento, DNA was extracted from 848 (506/ 540 ticks collected in EXTF and 342/360 in PATF). Larval blood meals were identified in 215 of these (25.4\% identification success; Table 3). Identification success varied widely between sampling sites (from 3.3 to $92.3 \%$; Table 1). The automated KingFisher ${ }^{\mathrm{rm}}$ technology tested here on 749 nymphs allowed DNA extraction from 96 samples per day by two operators, compared to 12 per day with QiaAmp ${ }^{\circ}$ DNA Investigator method, as well a two-thirds decrease in reagent cost. In addition, the robotic preparation of the PCR reactions decreased working time and possible errors associated with manual set-up.

The linear model identified DNA extraction method as the only factor that significantly affected identification success ( $\mathrm{t}$-value $=-4.99, d f=28, P=2.87 \mathrm{e}^{-5}$; Table 2). Hosts could be identified from tick nymphs $55.1 \%$ of the time if total DNA was extracted with QiaAmp ${ }^{\circ}$ DNA Investigator method compared to $22.4 \%$ identification success for total DNA extracted using the KingFisher ${ }^{\mathrm{ma}}$ Cell and Tissue DNA kit (Table 1). It should be noted that the amplicons from host DNA extracted from questing nymphs with the KingFisher $^{\mathrm{ru}}$ kit demonstrated a higher $T_{m}$ than those extracted with the QiaAmp DNA Investigator kit. If melting pattern was not sufficient to confirm a shift in $T_{m}$ sequencing was used to confirm the host species corresponding to the amplicons; the new melting temperatures were then used as reference $T_{m}$ (Additional file 1: Table S1).

The identification of the host species providing a larval blood meal was possible in 137 cases, while 102 hosts were identified to genus (67 for Apodemus spp.; nine for Sorex spp.; 19 for Turdus spp./E. rubecula and seven for Ovis

Table 2 Linear model results for blood meal identification success. Reference levels for the explanatory variables are QIAamp for 'Method', 2012 for 'Year', April for 'Month' and EXTF for 'habitat type'

\begin{tabular}{lcccl}
\hline Explanatory variable & Coefficient & $\mathrm{SE}^{\mathrm{a}}$ & $t_{\text {-value }}^{\mathrm{b}}$ & $\operatorname{Pr}(>\mid \mathrm{t})^{\mathrm{c}}$ \\
\hline (Intercept) & 58.62 & 7.82 & 7.44 & $<0.001$ \\
Method_KingFisher ${ }^{\mathrm{TM}}$ & -31.76 & 6.37 & -4.99 & $<0.001$ \\
Year_2013 & -3.21 & 6.33 & -0.51 & 0.62 \\
Month_May & -4.28 & 7.01 & -0.61 & 0.55 \\
Month_June & -4.74 & 9.29 & -0.51 & 0.61 \\
Habitat type_PATF & -0.38 & 5.29 & -0.07 & 0.94 \\
\hline
\end{tabular}

${ }^{\mathrm{a}}$ Standard error of estimated coefficient

${ }^{b} t$-value estimate to standard error ratio

'Probability for $t$-value spp.), as reported in Table 3. As explained in Collini et al. [11], HRMA could not reliably discriminate between $T$. philomelos and E. rubecula control samples as a result of overlapping $T_{m}$. In addition, when amplicons with a lower $T_{m}\left(84.10{ }^{\circ} \mathrm{C}, 84.14{ }^{\circ} \mathrm{C}\right.$ and $\left.84.24{ }^{\circ} \mathrm{C}\right)$ than usual for $T$. philomelos/E. rubecula $\left(84.44-84.50{ }^{\circ} \mathrm{C}\right)$ were sequenced, BLASTn could only identify them as Turdus spp. or T. philomelos; therefore, amplicons having a $T_{m}$ in the range 84.00 to $84.50{ }^{\circ} \mathrm{C}$ were all classified as Turdus spp./E. rubecula (Table 1). We also showed here that the Cervidae primer set amplifies a wider range of Cetartiodactyla hosts than predicted, including some species already targeted by the Caprinae primers (Ovis spp. and $R$. rupicapra), as well as fallow deer (Dama dama); however, sequence analysis of Ovis amplicons obtained with Cervidae primers indicated that HRMA of the control region fragment could not discriminate domestic (O. aries) and wild (O. aries musimon) sheep (BLASTn reports $99-100 \%$ identity scores for $O$. aries, $O$. a. musimon and O. orientalis; see Additional file 2: Table S2). Consequently, all sequences BLASTn matched with various sheep species or subspecies with a similar identity scores were classified as Ovis spp. Because $T_{m}$ of several species of Cervidae overlapped, identification by HRMA also became complex and all amplicons were sequenced to confirm species (Additional file 1: Table S1). In addition, HRMA with the Muroidea primer set led to the misidentification of five Apodemus spp. blood meals as $M$. glareolus, because of intraspecific variation caused by 2 to 9 nucleotide mutations (Additional file 3: Figure S1). A single blood meal from a Chinese hamster (Cricetus griseus) was also amplified using the Muroidea primers, producing an amplicon with a $T_{m}$ overlapping with that of Apodemus spp $\left(82.40{ }^{\circ} \mathrm{C}\right)$. We assume this blood meal originated from a companion animal since $C$. griseus does not occur naturally in Europe (such a result is unlikely to be due to contamination since samples of this species had not been processed previously in our laboratory).

Our results show that in Trentino, the most common larval hosts were Rodentia (28.9\%), mainly Apodemus spp. (28.0\%). The second most frequent host group was Carnivora (28.4\%), with C. l. familiaris accounting for $21.3 \%$ and V. vulpes for $7.1 \%$. Cetartiodactyla species fed $17.2 \%$ of larvae, with $C$. elaphus and C. capreolus being the most common hosts ( $6.3 \%$ and $4.2 \%$, respectively). The $14.6 \%$ of identified blood meals belonged to Passeriformes and, lastly, $10.9 \%$ of blood meals were derived from Soricomorpha. Of the entire list of target hosts, only $C$. russula, $S$. araneus and Mus musculus domesticus did not appear to be larval blood meal sources in the study area (Table 3).

Blood meal identification success was similar in EXTF (130/506; 25.7\%) and PATF (85/342; 24.9\%) sites (Table 3). The proportion of Soricomorpha blood meals was significantly higher in EXTF than in PATF (15.2 vs 4.3\%, respectively; $\chi^{2}=5.03, d f=1, P=0.014$ ), while the opposite 
Table 3 Blood meal identification in questing nymphs from EXTF and PATF in the Province of Trento, Italy

\begin{tabular}{|c|c|c|c|}
\hline \multirow{3}{*}{$\begin{array}{l}\text { Larval hosts targeted } \\
\text { (primer set used) }^{\mathrm{a}}\end{array}$} & \multicolumn{3}{|c|}{ Number and percentage of identified hosts in questing nymphs } \\
\hline & \multicolumn{2}{|l|}{ Forest type } & \multirow[t]{2}{*}{ Total $(\%)^{h}$} \\
\hline & EXTF $(\%)^{h}$ & PATF $(\%)^{h}$ & \\
\hline Rodentia (Muroidea) & $46(31.7)$ & $23(24.5)$ & $69(28.9)$ \\
\hline Apodemus spp. & $44(30.3)$ & $23(24.5)$ & $67(28.0)$ \\
\hline Myodes glareolus & $1(0.69)$ & 0 & $1(0.4)$ \\
\hline Mus musculus & 0 & 0 & 0 \\
\hline Cricetus griseus $^{\mathrm{b}}$ & $1(0.69)$ & 0 & $1(0.4)$ \\
\hline Carnivora (Canidae) & $33(22.7)$ & $35(37.2)$ & $68(28.4)$ \\
\hline Canis lupus familiaris & $28(19.3)$ & $23(24.5)$ & $51(21.3)$ \\
\hline Vulpes vulpes & $5(3.4)$ & $12(12.7)$ & $17(7.1)$ \\
\hline Cetartiodactyla (Caprinae, Cervidae) & $30(20.7)$ & $11(11.7)$ & $41(17.2)$ \\
\hline Ovis spp. ${ }^{c, d}$ & $5(3.4)$ & $2(2.1)$ & $7(2.9)$ \\
\hline Rupicapra rupicapra ${ }^{d}$ & $3(2.1)$ & 0 & $3(1.3)$ \\
\hline Capra hircus ${ }^{\mathrm{C}}$ & $2(1.4)$ & 0 & $2(0.8)$ \\
\hline Bos taurus ${ }^{c}$ & 0 & $3(3.2)$ & $3(1.3)$ \\
\hline Capreolus capreolus ${ }^{\mathrm{d}}$ & $8(5.5)$ & $2(2.1)$ & $10(4.2)$ \\
\hline Cervus elaphus $^{d}$ & $12(8.3)$ & $3(3.2)$ & $15(6.3)$ \\
\hline Dama dama ${ }^{b, d}$ & 0 & $1(1.1)$ & $1(0.4)$ \\
\hline Passeriformes (Passeriformes) & $14(9.6)$ & $21(22.3)$ & $35(14.6)$ \\
\hline Turdus merula & $8(5.5)$ & $8(8.5)$ & $16(6.7)$ \\
\hline Turdus spp./Erithacus rubecula ${ }^{\mathrm{e}}$ & $6(4.1)$ & $13(13.8)$ & $19(7.9)$ \\
\hline Soricomorpha (Soricidae) & $22(15.2)$ & $4(4.3)$ & $26(10.9)$ \\
\hline Sorex spp. & $9(6.2)$ & 0 & $9(3.8)$ \\
\hline Sorex araneus & 0 & 0 & 0 \\
\hline Crocidura leucodon & $7(4.8)$ & $2(2.1)$ & $9(3.8)$ \\
\hline Crocidura suaveolens & $6(4.1)$ & $2(2.1)$ & $8(3.3)$ \\
\hline Crocidura russula & 0 & 0 & 0 \\
\hline Total no. of nymphs analysed & 506 & 342 & 848 \\
\hline Total no. of nymphs with identified blood meal & 130 & 85 & 215 \\
\hline Total no. of hosts identified & 145 & 94 & 239 \\
\hline$\%$ identification success ${ }^{f}$ & 25.7 & 24.9 & 25.4 \\
\hline No. of mixed blood meals identified & 14 & 9 & 23 \\
\hline$\%$ of mixed blood meals ${ }^{9}$ & 10.8 & 10.6 & 10.7 \\
\hline
\end{tabular}

Abbreviations: EXTF extensive forest, PATF patchy forest

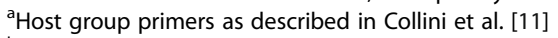

${ }^{b}$ Host not targeted in original protocol as described by Collini et al. [11], but identified here after HRMA, by sequencing and BLASTing

${ }^{\mathrm{C}}$ Amplified with Caprinae primers

${ }^{\mathrm{d} A m p l i f i e d}$ with Cervidae primers

eHRMA of Passeriformes amplicons did not allow discrimination between T. philomelos and E. rubecula

fTotal no. of nymphs with identified blood meal/total no. of nymphs analysed $* 100$

${ }^{9}$ Total no. of mixed blood meals identified/total no. of nymphs with identified blood meal * 100

${ }^{\text {h}}$ No. of identified host for taxonomic level/total no. hosts identified $* 100$

was true for Passeriformes (PATF: 22.3\% and EXTF: 9.6\%; $\left.\chi^{2}=4.29, d f=1, P=0.024\right)$ and, at the limit of significance, for Carnivora (PATF: $37.2 \%$ and EXTF: 22.8\%, respectively; $\chi^{2}=2.99, d f=1, P=0.063$ ), as presented in Fig. 2. No significant differences were observed between the proportion of Rodentia $(\mathrm{EXTF}=31.7 \%$; $\mathrm{PATF}=24.5 \%$;
$\left.X^{2}=0.68, d f=1, P=0.337\right)$ or Cetartiodactyla (EXTF $=$ $20.7 \%$; PATF $\left.=11.7 \% ; X^{2}=1.97, d f=1, P=0.114\right)$ acting as larval hosts in the two forest habitats (Fig. 2).

Interestingly, DNA from multiple hosts was recovered simultaneously from 23 nymphs (10.7\%; Tables 1, 4). All mixed blood meals consisted of DNA from two hosts, 


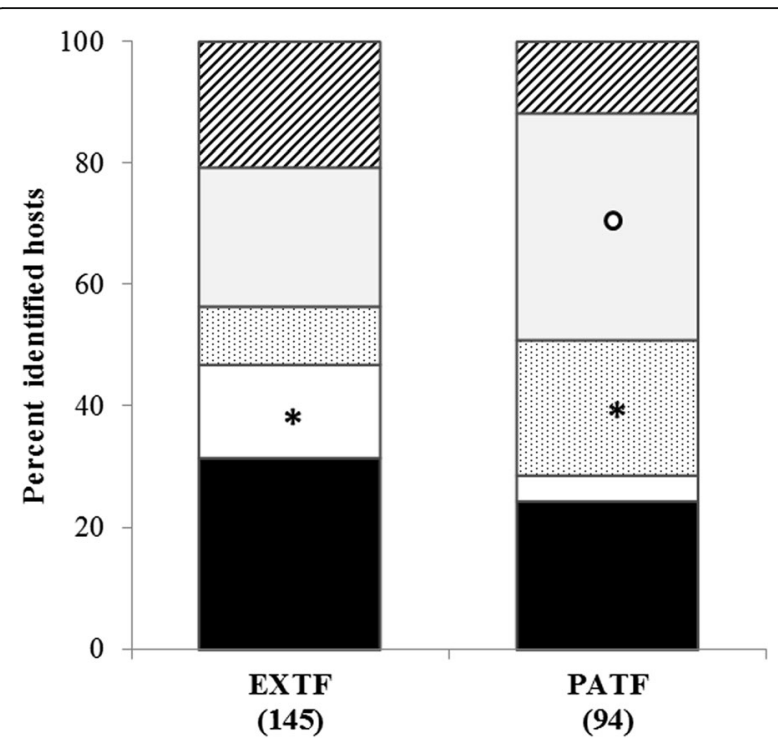

Fig. 2 Percent of I. ricinus larvae hosts from the five taxonomic orders, according to habitat type: Cetartiodactyla (diagonal stripes), Carnivora (light grey), Passeriformes (stippled), Soricomorpha (white), Rodentia (black). Chi-square test: ${ }^{*} P<0.05 ; \mathrm{oP}<0.10$

except one for which three hosts (Apodemus spp., Turdus spp./E. rubecula and Ovis spp.) were identified. The most prevalent host in this group of blood meals, Apodemus spp., was found in association with eight other hosts in 13 nymphs; the second most prevalent, $C$. l. familiaris, was found together with 4 different hosts in 9 nymphs (Table 4). It should be noted that DNA from multiple hosts in single nymphs was obtained by independent amplifications with the different primer sets, supporting the reliability of their identification.

\section{Discussion}

This study shows that the real-time HRMA protocol for blood meal analysis in questing tick nymphs of Collini et al. [11] is a reliable method for the identification of at least 20 larval host species and genera. Moreover, the introduction of the automated DNA extraction method and the robotic preparation of PCR reactions improved the time- and costeffectiveness of the HRMA protocol for blood meal analysis presented here. However, there was a notable decrease in the identification success noted here $(25.4 \%$ overall $)$ compared to the $65.4 \%$ reported in Collini et al. [11] based on manual DNA extraction and PCR set-up only, and to other blood meal analysis methods (RLBH: 26.4\% [17], 53.1\% [18], 49.4\% [19], 33.0\% [20], 43,6\% [21], 62.8\% [22]; RFLP: $62.8 \%$ [23]). We assume this decrease was a direct result of the DNA extraction method, although site-specific climatic conditions may also have had an effect, as noted by Morán Cadenas et al. [21]. Unfortunately, we do not have the relevant measurements at our sample sites of the most important climatic variables regulating tick activity, such as saturation deficit [24], which would have allowed an investigation of this effect.

Here we also extended the list of hosts detected by the primer sets for the Cervidae (from two to five with the addition of D. dama, Ovis spp. and $R$. rupicapra) and Passeriformes (from two to three with the addition of Turdus spp.). On one hand, extending the host species list improves the accuracy of the method in reliably assessing host richness; on the other, since primer targets within host groups have relatively low levels of variability, the $T_{m}$ overlapped for some species, and therefore amplicons needed to be sequenced to confirm species identification. Sequencing could be avoided if identification of host group or genus is adequate for answering the scientific question of the study; for example, our results showed that grouping hosts by Order still gave important insight into larval host distribution in the habitats investigated here. However, possible solutions exist to enhance species-level identification, such as the use of unlabeled probes [25] or a secondary HRMA on the heteroduplexes formed between the reference and the unknown amplicons [26]. It might be particularly interesting to discriminate between blood meals derived from wild and domestic sheep, since it was recently noted that wild relatives of domesticated species may be

Table 4 Number of mixed larval blood meals with specific host compositions

\begin{tabular}{|c|c|c|c|c|c|c|}
\hline & Apodemus spp. & Sorex spp. & Vulpes vulpes & Capreolus capreolus & Cervus elaphus & Bos taurus \\
\hline Apodemus spp. & & & 1 & & 2 & \\
\hline Myodes glareolus & & & & 1 & & \\
\hline Crocidura leucodon & & & 2 & & 1 & \\
\hline Crocidura suaveolens & 1 & & & & & \\
\hline Turdus merula & 1 & & & & & \\
\hline Turdus spp/Erithacus rubecula & $2^{a}$ & & 1 & & & \\
\hline Canis lupus familiaris & 4 & 1 & & & 1 & 3 \\
\hline Ovis spp. & $1^{\mathrm{a}}$ & & & & & \\
\hline Capra hircus & 1 & & & & & \\
\hline
\end{tabular}

${ }^{\mathrm{a}}$ From a single nymph, DNA from Apodemus spp., Turdus. spp./E. rubecula and Ovis spp. was identified 
unrecognized reservoirs of zoonotic pathogens (see [3] and references therein; [27]). Since mutations can also confound species identification in the Muroidea, the above suggestions may prove useful for identifying host species in this group as well.

Despite the problems encountered above, we believe that this method, which eliminates contamination, a troublesome feature of previous methods, is still a valuable tool in the study of the feeding ecology of hard ticks. A variety of possibilities still exist for its improvement, from the DNA extraction method to host identification. For example, considering the importance of lizards in some TBDs, the panel of targeted hosts could be enhanced accordingly as a future improvement of the HRMA assay.

The application of the HRMA protocol to a large number of tick nymphs from across the Province of Trento has lent insight into the feeding ecology of larval ticks, and TBDs risk in this area. As forests cover over $50 \%$ of the province, villages and other residential areas are embedded in a rural ecosystem where work and leisure activities promote close contact with tick habitat. In addition, local wildlife includes many of the species recognized as competent reservoirs for zoonotic pathogens, as well as tick spreaders and maintenance hosts $[3,28]$. Our data confirmed that Apodemus spp. are the most important larval hosts, providing $28.0 \%$ of blood meals, while passerine birds accounted for another $14.6 \%$. With rodent meals and, less frequently, bird blood meals, larval ticks may acquire pathogens such as $B$. burgdorferi (s.l.), TBEv and Anaplasma phagocytophilum [3, 29-33]. The pathogens multiply in the salivary glands of the tick and may be transmitted to the next host, including humans, establishing the basis for disease hazard as a result of infected tick presence in both forest habitats [8]. In addition, ungulates like $C$. capreolus and C. elaphus are known to be critical to the maintenance of the sylvatic cycle of these pathogens, as they feed ticks at various stages $[33,34]$. Our analyses indicate that species of Cetartiodactyla are important larval hosts in both PATF and EXTF (17.2\% overall), with C. capreolus and C. elaphus being the most represented (4.2 and $6.3 \%$ respectively), meaning that TBDs cycles are well-supported across the study area.

This is the first blood meal study to consider domestic dogs as larval tick hosts. Unexpectedly, our results show that species of Carnivora are as important as rodents in providing larval blood meals $(28.4 \%)$ in the study area. Of the 51 amplicons identified by HRMA as C. l. familiaris, 19 were sequenced and all of them identified as C. l. familiaris with a $99-100 \%$ of identity score by BLASTn (https://blast.ncbi.nlm.nih.gov/Blast.cgi). Additionally, as reported in Additional file 1: Table S1, HRMA discrimination between $C$. l. familiaris and $V$. vulpes was straightforward thanks to their particular discriminant melting temperatures and to differences in the number of peaks (a single peak for dogs and two peaks for foxes). As for other wild European carnivores (badger Meles meles and raccoon dog Nyctereutes procyonoides [35]; marbled polecat Vormela peregusna and European mink Mustela lutreola [36]), the role of dogs and foxes in the epidemiology of TBDs is still not well-defined as they do not appear to be amplification hosts for TBEv [37], or reservoir hosts for Borrelia burgdorferi (s.l.) [38] or A. phagocytophilum [28, 39], although all of these mammal species are known to carry these pathogens. Most importantly for human tick bite and TBD risk, dogs appear to be important hosts in both EXTF and PATF. This means they contribute to maintaining TBD cycles as tick feeders in both habitats, but could also carry infected ticks from EXTF and/or PATF into urban parks, gardens and houses where they may later drop off and parasitize a variety of urbanadapted vertebrate tick hosts including humans [3, 38, 40-43]. The potential impact of domestic dogs and foxes on TBD cycles definitely deserves further attention. In addition, dogs may represent a target for tick population control in urbanized areas, and could act as sentinels for TBDs [38, 44].

It has recently been suggested that domesticated hosts, such as dogs (but also cats, cattle, sheep and goats), are potential tick and pathogens super-spreaders, connecting epidemiological systems involving different tick species, vertebrate hosts and pathogens [4]. Our study confirms that larval I. ricinus feeds equally on many wild and domesticated hosts in the same habitat; moreover, in the same study area, tick species other than I. ricinus have been found feeding on dogs and birds [45]. Since our study also shows that ground-feeding passerine species are more important larval hosts in PATF than EXTF, being common in urban green areas, we would add that these Passeriformes, together with foxes, could also be considered additional spreader species. Only Soricomorpha, that are generally negatively affected by habitat fragmentation and agricultural activities [46, 47], are more represented in EXTF, and are unlikely to act as bridge species; however, as they feed more than $10 \%$ of tick larvae and given their recognized reservoir status for some pathogens, their role in the wild TBD cycles should not be underestimated [48].

DNA of more than one host was detected in 10.7\% of single nymphs, in agreement with previous studies $[21,22,49]$. While it has been suggested that mixed blood meals are the result of contamination, this is unlikely in our study since all DNA extraction and amplification controls were negative. In addition, mixed blood meals were unambiguous, as hosts were identified in independent reactions with different host-group specific primer sets. Although multiple host blood meals run contrary to the widely held view that $I$. ricinus takes one blood meal from a single host 
per life stage (see Background), Gray et al. [49] also observed the occasional collection of semi-engorged larvae by blanket dragging, suggesting that multiple blood meals are occasionally necessary for full engorgement, after voluntary drop off, involuntary interrupted feeding, or unsuccessful full attachment. We observed that many different host combinations are possible (see Table 4): two rodents, rodent and bird, rodent and carnivore, rodent and ungulate, etc., presumably not only resulting in mixed blood meals, but also promoting multiple pathogen transmission between hosts. This phenomenon deserves a more in depth analysis, especially in view of the fact that pathogen co-infections in questing ticks at both nymph and adult stages have also been widely observed [18-20, 50-53], and notably, such multiple infections from a single tick bite in humans have clinical symptoms showing complex patterns making diagnosis and prophylaxis challenging [54, 55]. Multiple infections have been explained up to now by transtadial/ transovarial pathogen transmission and acquisition of additional pathogens by successive meals taken at different stages [52, 53]; however, a significant source of such coinfection could derive from repetitive blood meals at the same stage.

\section{Conclusions}

The HRMA protocol of Collini et al. [11] is a reliable method for larval blood meal analysis in field-collected sheep tick nymphs, although identification success is lower if DNA extraction is automated and sequencing of amplicons is still necessary for species confirmation with several primer sets. The results obtained from 848 ticks from 30 sites across the Province of Trento show that rodents and wild ungulates are widely exploited as larval blood meal sources, supporting TBDs sylvatic cycles across the study area. In addition, we have also shown for the first time that domestic dogs are important larval tick hosts, with possible implications not only for tick population maintenance and spread of TBD in urban and semi-urban areas, but also for tick control strategies.

\section{Additional files}

Additional file 1: Table S1. Melting temperatures for amplicons obtained from questing tick extracted using the KingFisher Cell and Tissue kit. (PDF $415 \mathrm{~kb}$ )

Additional file 2: Table S2. BLASTn search results and alignment for Ovis spp. amplicons obtained with Cervidae primer set. (PDF 323 kb)

Additional file 3: Figure S1. Sequence alignment of mtDNA control region amplicons generated with the Muroidea primer set. (PDF 307 kb)

\section{Abbreviations}

DNA: Deoxyribonucleic acid; EXTF: Extensive forest; HRMA: High resolution melting analysis; mtDNA: Mitochondrial DNA; PATF: Forest patches surrounding human settlements; PCR: Polymerase chain reaction; RFLP: Restriction length fragment polymorhisms; RLBH: Reverse line blot hybridization; $T_{m}$ : Melting temperature; TBD: Tick-borne disease

\section{Acknowledgements}

We especially thank Benjamin Fowle, Kieran D. O'Malley and Alessandra Fauri for their help with tick DNA extraction, and Matteo Girardi and Barbara Crestanello for laboratory support.

\section{Funding}

We thank the European Union grant FP7-261504 EDENext, the Autonomous Province of Trento, the Fondazione Edmund Mach, and the Università degli Studi di Milano for funding and support. Funding bodies played no role in study design, in the collection, analysis and interpretation of data, in the writing of the report, and in the decision to submit the article for publication. This article is catalogued by the EDENext Steering Committee as EDENext 381 (http://www.edenext.eu).

The contents of this publication are the sole responsibility of the authors and do not necessarily reflect the views of the European Commission.

\section{Availability of data and materials}

The datasets supporting the conclusions of this article are included within the article and its additional files.

\section{Authors' contributions}

$\mathrm{MC}$ and $\mathrm{HCH}$ designed the sampling strategy and wrote the first draft; $\mathrm{MC}$ and FA optimized the HRMA in collaboration with LC, CR and MM; DA and $V T$ were responsible for much of the field collection together with $M C$; RR carried out the statistical analyses; $\mathrm{AR}$ and $\mathrm{HCH}$ were responsible for writing the project and acquiring the funding; all authors contributed substantially to the manuscript. All authors read and approved the final manuscript.

\section{Competing interests}

The authors declare that they have no competing interests.

Consent for publication

Not applicable.

\section{Ethics approval and consent to participate}

Permission to carry out the trapping in the defined areas and all animal handling procedures were authorized by the Comitato Faunistico Provinciale della Provincia di Trento prot. n. 595 04.05.2011. Ethical guidelines concerning animal welfare were followed as defined by the European Commission and detailed in the EDENext project (http://www.edenext.eu).

\section{Author details}

${ }^{1}$ Department of Biodiversity and Molecular Ecology, Research and Innovation Centre, Fondazione Edmund Mach, San Michele all'Adige, Trento, Italy. ${ }^{2}$ Department of Veterinary Medicine, Università degli Studi di Milano, Milan Italy. ${ }^{3}$ Department of Food Quality and Nutrition, Research and Innovation Centre, Fondazione Edmund Mach, San Michele all'Adige, Trento, Italy.

Received: 20 June 2016 Accepted: 21 November 2016

Published online: 12 December 2016

\section{References}

1. Parola P, Raoult D. Ticks and tick-borne bacterial diseases in humans: an emerging infectious threat. Clin Infect Dis. 2001;32:897-928.

2. Heyman P, Cochez C, Hofhuis A, Van der Giessen J, Sprong H, Porter SR, et al. A clear and present danger: tick-borne diseases in Europe. Expert Rev Anti-Infe. 2010;8:33-50

3. Rizzoli A, Silaghi C, Obiegala A, Rudolf I, Hubálek Z, Földvári G, et al. Ixodes ricinus and its transmitted pathogens in urban and peri-urban areas in Europe: new hazards and relevance for public health. Front Public Health. 2014;2:251.

4. Estrada-Peña A, de la Fuente J, Ostfeld RS, Cabezas-Cruz A. Interactions between tick and transmitted pathogens evolved to minimise competition through nested and coherent networks. Sci Rep. 2015:5:10361.

5. Mukabana WR, Takken W, Knols BGJ. Analysis of arthropod bloodmeals using molecular genetic markers. Trends Parasitol. 2002;18:505-9.

6. Kent RJ. Molecular methods for arthropod bloodmeal identification and applications to ecological and vector-borne disease studies. Mol Ecol Res. 2009;9:4-18.

7. Gómez-Díaz E, Fiquerola J. New perspectives in tracing vector-borne interaction networks. Trends Parasitol. 2010;26:470-6. 
8. Bolzoni L, Rosà R, Cagnacci F, Rizzoli A. Effect of deer density on tick infestation of rodents and the hazard of tick-borne encephalitis. II: Population and infection models. Int J Parasitol. 2012;42:373-81.

9. Kirstein F, Gray JS. A molecular marker for the identification of the zoonotic reservoirs of Lyme borreliosis by analysis of the blood meal in its European vector Ixodes ricinus. Appl Environ Microb. 1996;62:4060-5.

10. Estrada-Peña A, Osàcar JJ, Pichon B, Gray JS. Host and pathogen detection for immature stages of Ixodes ricinus (Acari: Ixodidae) in North-Central Spain. Exp Appl Acarol. 2005;37:257-68.

11. Collini M, Albonico F, Hauffe HC, Mortarino M. Identifying the last bloodmeal of questing sheep tick nymphs (Ixodes ricinus L.) using high resolution melting analysis. Vet Par. 2015;210:194-205.

12. Estrada-Peña A, Gray JS, Kahl O, Lane RS, Nijhof AM. Research on the ecology of ticks and tick-borne pathogens - methodological principles and caveats. Front Cell Infect Microbiol. 2013:3:29.

13. Collini M, Hauffe HC, Masséglia S, Albonico F, Arnoldi D, Bailly X, et al. Identifying the last bloodmeal of questing wood tick nymphs (Ixodes ricinus L.) by DNA amplification: three approaches tested. Heraklion, Crete, Greece, "Genes, Ecosystems and Risk of Infections", 21-23 $3^{\text {rd }}$ April 2015, http://geri2015. edenext.eu/content/download/4186/31373/version/1/file/P+2.18.pdf.

14. Sonenshine DE. Biology of Ticks, volume 2. Appendix. New York: Oxford University Press; 1993. p. 397-400.

15. Cringoli G, lori A, Rinaldi L, Veneziano V, Genchi C. Zecche. Mappe Parassitologiche. Napoli: Rolando Editore; 2005.

16. R Development Core Team. R: a language and environment for statistical computing. Vienna: R Foundation for Statistical Computing; 2014. URL: http://www.R-project.org.

17. Bown KJ, Lambin X, Ogden NH, Begon M, Telford G, Woldehiwet Z, et al. Delineating Anaplasma phagocytophilum ecotypes in coexisting, discrete enzoonotic cycles. Emerg Infect Dis. 2009;15:1948-54

18. Pichon B, Egan D, Rogers M, Gray J. Detection and identification of pathogens and host DNA in unfed host-seeking /xodes ricinus L. (Acari: Ixodidae). J Med Entomol. 2003;40:723-31

19. Pichon B, Rogers M, Egan D, Gray J. Blood-meal analysis for the identification of reservoir hosts of tick-borne pathogens in Ireland. VectorBorne Zoonotic Dis. 2005;5:172-80.

20. Pichon B, Kahl O, Hammer B, Gray JS. Pathogens and host DNA in Ixodes ricinus nymphal ticks from a German forest. Vector-Borne Zoonotic Dis. 2006;6:382-7.

21. Morán Cadenas F, Rais O, Humair PF, Douet V, Moret J, Gern L. Identification of host bloodmeal source and Borrelia burgdorferi sensu lato in fieldcollected Ixodes ricinus ticks in Chaumont (Switzerland). J Med Entomol. 2007:44:1109-17.

22. Allan BF, Goessling LS, Storch GA, Thach RE. Blood meal analysis to identify reservoir hosts for Amblyomma americanum ticks. Emerg Infect Dis. 2010;16: 433-40.

23. Wodecka B, Rymaszewska A, Skotarczak B. Host and pathogen identification in blood meals of nymphal Ixodes ricinus ticks from forest parks and rural forest of Poland. Exp Appl Acarol. 2014;62:543-55.

24. Tagliapietra V, Rosà R, Arnoldi D, Cagnacci F, Capelli G, Montarsi F, et al. Saturation deficit and deer density affect questing activity and local abundance of /xodes ricinus (Acari, Ixodidae) in Italy. Vet Parasitol. 2011;183:114-24.

25. Reed GH, Kent JO, Wittwer $\mathrm{CT}$. High-resolution DNA melting analysis for simple and efficient molecular diagnostics. Pharmacogenomics. 2007:8:597-608.

26. Cheng JC, Huang CL, Lin CC, Chen CC, Chang YC, Chang SS, et al. Rapid detection and identification of important bacteria by high-resolution melting analysis after broad-range ribosomial RNA real-time PCR. Clin Chem. 2006;52:1997-2004.

27. López-Olvera JR, Vidal D, Vicente J, Pérez M, Luján L, Gortázar C. Serological survey of selected infectious diseases in mouflon (Ovis aries musimon) from south-central Spain. Eur J Wildl Res. 2009;55:75-9.

28. Stuen S, Granquist EG, Silaghi C. Anaplasma phagocytophilum - a widespread multi-host pathogen with highly adaptive strategies. Front Cell Infect Microbiol. 2013;3:31.

29. Waldenström J, Lundkvist A, Falk KI, Bergström S, Lindgren G, Sjösted A, et al. Migrating birds and tick-borne encephalitis virus. Emerg Infect Dis. 2007;13:1215-8.

30. Lommano E, Dvořák C, Vallotton L, Jenni L, Gern L. Tick-borne pathogens in ticks collected from breeding and migratory birds in Switzerland. Ticks Tick Borne Dis. 2014:5:871-82.

31. Rizzoli A, Hauffe HC, Carpi G, Vourc'h GI, Neteler M, Rosà R. Lyme borreliosis in Europe. Euro Surveill. 2011; 16(27):pii = 19906. http://www.eurosurveillance.org/ ViewArticle.aspx?Articleld=19906.
32. Mantke OD, Escadafal C, Niedrig M, Pfeffer M, on behalf of the Working group foe Tick-borne encephalitis virus. Tick-borne encephalitis in Europe, 2007 to 2009, Euro Surveill, 2011; 16(39):pii = 19976. http://www.eurosurveillance.org/ ViewArticle.aspx?Articleld=19976.

33. Rizzoli A, Heidi HC, Tagliapietra V, Neteler M, Rosà R. Forest structure and roe deer abundance predict tick-borne encephalitis risk in Italy. PLoS One. 2009;4:e4336.

34. Carpi G, Cagnacci F, Neteler M, Rizzoli A. Tick infestation on roe deer in relation to geographic and remotely sensed climatic variables in a tickborne encephalitis endemic area. Epidemiol Infect. 2008;136:1416-24.

35. Wodecka B, Michalik J, Lane RS, Nowak-Chmura M, Wierzbicka A. Differential associations of Borrelia species with European badgers (Meles meles) and raccoon dogs (Nyctereutes procyonoides) in western Poland. Ticks Tick Borne Dis. 2016;7:1010-6.

36. Gherman CM, Sándor AD, Kalmár Z, Marinov M, Mihalca A. First report of Borrelia burgdorferi sensu lato in two threatened carnvores: the Marbled polecat, Vormela peregusna and the European mink, Mustela lutreola (Mammalia: Mustelidae). BMC Vet Res. 2012;8:137-40.

37. Pfeffer M, Dobler G. Tick-borne encephalitis virus in dogs - is this an issue? Parasit Vectors. 2011:4:59.

38. Bhide M, Travnicek M, Curlik J, Stefancikova A. The importance of dogs in ecoepidemiology of Lyme borreliosis: a review. Vet Med-Czech. 2004;4:135-42.

39. Carrade DD, Foley JE, Borjesson DL, Sykes JE. Canine granulocytic anaplasmosis: a review. J Vet Intern Med. 2009;23:1129-41.

40. Trotta M, Nicetto M, Fogliazza A, Montarsi F, Caldin M, Furlanello T, et al. Detection of Leishmania infantum, Babesia canis, and rickettsiae in ticks removed from dogs living in Italy. Ticks Tick Borne Dis. 2012;3:294-7.

41. Farkas R, Gyurkovszky M, Lukás Z, Aladics B, Solymosi N. Seroprevalence of some vector-borne infections of dogs in Hungary. Vector Borne Zoonotic Dis. 2014;14:256-60

42. Uspensky I. Tick pests and vectors (Acari: Ixodidea) in European towns: Introduction, persistence and management. Ticks Tick Borne Dis. 2014;5:41-7.

43. Manckested $U$, Jenkins $D$, Roming $T$. The role of wildlife in the transmission of parasitic zoonoses in peri-urban and urban areas. Int J Parasitol Parasites Wild. 2015:4:71-9.

44. Smith FD, Ballantyne R, Morgan ER, Wall R. Estimating Lyme disease risk using pet dogs as sentinels. Comp Immunol Microb. 2012:35:163-7.

45. Baráková I, Derdáková M, Carpi G, Rosso F, Collini M, Tagliapietra V, et al. Genetic and ecologic variability among strains of Anaplasma phagocytophilum, northern Italy. Emerg Infect Dis. 2014;20:1082-5.

46. Canova L, Fasola M. Communities of small mammals in six biotopes of northern Italy. Acta Theriol. 1991;36:73-86.

47. Spinozzi F, Battisti C, Bologna MA. Habitat fragmentation sensitivity in mammals: a target selection for landscape planning comparing two different approaches (bibliographic review and expert based). Rend Lincei Sci Fis Nat. 2012;23:365-73.

48. Bown KJ, Lambin X, Telford G, Heyder-Bruckner D, Ogden NH, Birtles RJ. The common shrew (Sorex araneus): a neglected host of tick-borne infections? Vector Borne Zoonotic Dis. 2011;11:947-53.

49. Gray JS, Kirstein F, Robertson JN, Stein J, Kahl O. Borrelia burgdorferi sensu lato in Ixodes ricinus ticks and rodents in a recreational park in southwestern Ireland. Exp Appl Acarol. 1999;23:717-29.

50. Leutenegger CM, Pusterla N, Mislin CN, Weber R, Lutz H. Molecular evidence of coinfection of ticks with Borrelia burgdorferi sensu lato and the human granulocytic ehrlichiosis agent in Switzerland. J Clin Microbiol. 1999;37:3390-1.

51. Kurtenbach K, De Michelis S, Sewel H-S, Etti S, Schäfer SM, Hails R, et al. Distinct combinations of Borrelia burgdorferi sensu lato genospecies found in individual questing ticks from Europe. Appl Environ Microbiol. 2001;67:4926-9.

52. Swanson SJ, Neitzel D, Reed KD, Belongia EA. Coinfections acquired from Ixodes ticks. Clin Microbiol Rev. 2006;19:708-27.

53. Reis C, Cote M, Paul REL, Bonnet S. Questing ticks in suburban forest are infected by at least six tick-borne pathogens. Vector Borne Zoonotic Dis. 2011;11:907-16.

54. Mitchell PD, Reed KD, Hofkes JM. Immunoserologic evidence of coinfection with Borrelia burgdorferi, Babesia microti, and human granulocytic Ehrlichia species in residents of Wisconsin and Minnesota. J Clin Microbiol. 1996;34:724-7.

55. Nadelman RB, Horowitz HW, Hsieh TC, Wu JM, Agueri-Rosenfeld ME, Schwartz I, et al. Simultaneous human granulocytic ehrlichiosis and Lyme borrelliosis. N Engl J Med. 1997;337:27-30. 